\title{
Nutri-jelly may improve quality of life and decrease tube feeding demand in head and neck cancer patients
}

\author{
Dunyaporn Trachootham - Wasinee Songkaew - Buakhao Hongsachum • \\ Chodchoi Wattana - Nanchaporn Changkluengdee - Jandanee Karapoch • \\ Sureerat Thirdsuttironnapumi • Ekapop Meennuch • Chonsanee Klaitong • \\ Tanadej Sinthusek • Aroonwan Lam-ubol
}

Received: 28 May 2014 / Accepted: 17 October 2014 /Published online: 5 November 2014

(C) The Author(s) 2014. This article is published with open access at Springerlink.com

\begin{abstract}
Purpose Eating difficulty is a critical and common problem in head and neck cancer patients undergoing radiotherapy (RT). It leads to poor quality of life and extensive tube feeding use.
\end{abstract}

Electronic supplementary material The online version of this article (doi:10.1007/s00520-014-2488-5) contains supplementary material, which is available to authorized users.

D. Trachootham $(\square) \cdot$ J. Karapoch

Institute of Nutrition, Mahidol University, 999 Phutthamonthon 4

Rd., Salaya, Phutthamonthon, Nakhon Pathom 73170, Thailand

e-mail: dif.dunyaporn@gmail.com

D. Trachootham

e-mail: dunyaporn.tra@mahidol.ac.th

D. Trachootham

Faculty of Dentistry, Thammasat University, Pathum Thani, Thailand

W. Songkaew $\cdot$ N. Changkluengdee $\cdot S$. Thirdsuttironnapumi $\cdot$

E. Meennuch $\cdot$ C. Klaitong $\cdot$ T. Sinthusek

Mahavachiralongkorn Cancer Hospital, Pathum Thani, Thailand

B. Hongsachum

Dental Innovation Foundation Under Royal Patronage, His Majesty

the King's Dental Service Unit, Bangkok, Thailand

C. Wattana

Faculty of Nursing, Thammasat University, Pathum Thani, Thailand

C. Wattana

Center of Excellence in Chronic Care, Phrapokklao Nursing College,

Chanthaburi, Thailand

J. Karapoch

Nutrition Therapeutics Department, Samitivej Sukhumvit Hospital,

Bangkok, Thailand

\section{A. Lam-ubol}

Faculty of Dentistry, Srinakharinwirot University, Bangkok,

Thailand
Nutri-jelly, a food gel with semisolid texture, water-releasing ability, and ready-to-eat by spoon, was recently developed to alleviate the trouble. However, its efficacy was unknown. This study investigated the potential effect of Nutri-jelly on healthrelated quality of life (HRQOL) and nasogastric tube feeding use.

Methods A prospective quasi-randomized patients-preference controlled trial was conducted in 74 head and neck cancer patients. Subjects in study and control groups (37 each) had similar baseline HRQOL and body mass index and undergone definitive radiotherapy (25-35 RT fractions, 5,000-7,000 cGy). Only study group received a $200-\mathrm{ml}$ box of Nutri-jelly as daily supplement throughout radiotherapy. HRQOL was scored by validated questionnaires. The use of tube feeding was collected from medical records.

Results From 11 to 35 RT fractions, the study group maintained higher overall HRQOL score than that of control group $(p<0.0001)$. Multiple physiologic and psychological aspects of HRQOL especially swallowing difficulty and overall eating problems were significantly improved in study as compared to control group. Promisingly, the percentage of tube feeding use in study group (13.5\%) was dramatically lower than control group $(48.6 \%)$.

Conclusions Continuous supplementation of Nutri-jelly throughout radiotherapy may improve HRQOL and reduce tube feeding demand in head and neck cancer patients who preferred to take them. Nutri-jelly could be an alternative for head and neck cancer patients who have eating difficulty during radiotherapy.

Keywords Head and neck cancer · Clinical trial · Radiotherapy · Side effects · Quality of life · Dietary management $\cdot$ Dysphagia 


\section{Introduction}

Radiotherapy (RT) is among the most effective treatments for head and neck cancer. However, many patients suffer from side effects, posting challenges in treatment success. Common adverse consequences include oral mucositis, mouth pain, dry mouth, taste loss, difficulty in mouth opening (trismus), and fibrosis of pharyngeal muscles [1]. Furthermore, the patients often lose numerous teeth during pre-radiation mouth preparation. These lead to difficulties in chewing and swallowing, malnutrition, poor quality of life, and poor response to treatment [2-6]. Currently, tube feeding is a standard nutritional intervention leading to significant improvement in body weight [7]. Unfortunately, the procedure was invasive, and its effect on quality of life and mortality was inconsistent [8]. Furthermore, extended hospitalization due to tube feeding leaves burden to caregivers and increases risk of aspiration pneumonia and mortality [9]. Therefore, new noninvasive approaches to overcome the eating difficulty are essential [10].

In recent years, oral nutritious supplements have gained much of attention and proven to reduce weight loss [11]. Meta-analysis showed that oral supplementation with nutritious substances can improve certain aspects of life's quality but have no effect on patients' survival [12]. Currently available oral nutritional supplements are in powder and liquid forms. However, the powder forms are not ready to eat, and the liquid form is not adequate to stimulate mastication and oral swallowing. Limited oral muscular movement in tube-fed patients could decrease salivary flow and quality, reduce oral clearances, and increase bacteria colonization and risk of oral diseases [13, 14]. Although thickened liquid had been used in treatment of dysphagia for decades, oral dehydration is a common side effect from this intervention [15]. Therefore, its application in patients with xerostomia was limited. Furthermore, most people feel completely sick while on liquid diet. And, feeling ill is a predictor of poor survival in head and neck cancer [16]. Therefore, the ideal oral supplement for cancer patients should be ready-to-eat, most resemble to regular food (solid-like), chewable, moisten, and easy to swallow.

Recently, Nutri-jelly was successfully developed by collaboration of various experts. This product is a readyto-eat nutritious gel with $230-260 \mathrm{kcal}$ per serving $(1 \mathrm{kcal} / 1 \mathrm{ml})$. It has solid appearance but can be melted under oral environment temperature [17]. Upon biting or spooning, the food gel will release some water due to syneresis [18]. Optimum gel texture was identified and proved easily to swallow by $95 \%$ of 115 head and neck cancer patients suffering from eating troubles [17]. Furthermore, $80 \%$ of 120 patients were satisfied with the texture, flavor, and moisture of Nutri-jelly [17]. Although it was proved edible by head and neck cancer patients, its benefit to quality of life and its impact on tube feeding demand were unknown.

The purpose of this study was to investigate the potential effect of Nutri-jelly on health-related quality of life (HRQOL) and nasogastric (NG) tube feeding use in head and neck cancer patients undergoing definitive radiotherapy.

\section{Methods}

Intervention

Nutri-jelly products were provided by the Dental Innovation Foundation under Royal Patronage. The product was certified by Thai Food and Drug Administration (FDA) and HALAL. It was manufactured in ultra-high temperature (UHT) processing and aseptic filling system by Ampol Food Processing Co., Ltd under international standard (Good Manufacturing Practice (GMP), Hazard Analysis and Critical Control Points (HACCP), and International Organization for Standardization (ISO) 22000). The shelf-life at room temperature is 1 year. There are two flavors: Thai tea and mango (Fig. 1a). The product has semisolid texture, water-releasing ability, and is ready-to-eat by spoon (Fig. 1b). One serving (one box) contains $230 \mathrm{kcal}$ (Thai tea flavor) and $260 \mathrm{kcal}$ (mango flavor). The nutrition fact of each flavor was shown in Fig. 1c. Each $1 \mathrm{~g}$ of Nutri-jelly contains $1 \mathrm{kcal}$. Sources of energy were from carbohydrate, fat, and protein in the ratio of 50:30:20, respectively.

\section{Participants}

Inclusion criteria were as follows: being diagnosed with head and neck cancer patients with International Classification of Disease (ICD) 10, C00-C14 and C31-C32 and undergoing definitive radiotherapy (25-35 (RT) fractions, 5,000-7,000 centigrays (cGy) with Cobalt-60 radiation. Exclusion criteria were as follows: having active oral bleeding, difficult breathing, extremely poor life's quality (baseline HRQOL score $<4$ ), and being unable to make reliable decision or effective communication. All subjects signed their written informed consent prior to inclusion in the study. Their identities have been protected.

\section{Sample size calculation}

The estimated sample size was identified by priori power analysis using G Power 3.1 [19]. The effect size was calculated from pilot data (mean overall HRQOL and standard deviation (SD) of ten control subjects at baseline (0-5 RT), 6-10, 11-15, 16-20, 21-25, and 26-35 RT fractions. Based on analysis of variance, we need to enroll 24 subjects per group to achieve $90 \%$ power at a two-sided $1 \%$ significance level. To account for an up to $30 \%$ dropout rate, at least 32 patients were required in each group. Initially, 80 patients agreed to be enrolled in the study. Finally, 
Fig. 1 Nutri-jelly. a The packages of Nutri-jelly in UHT brix: mango flavor (yellow label) and milk tea flavor (brown). b Texture of Nutri-jelly is semisolid (left image). Upon cut or bitten, water will be released from the gel (middle image). The patients on NG tube feeding can eat it with spoon, like regular food (right image). $\mathbf{c}$ Nutrition fact of mangoand milk-tea-flavored Nutri-jelly. One serving contains 260 or $230 \mathrm{kcal}$ as shown. The percentages of nutrient are based on Thai RDI

\section{a}

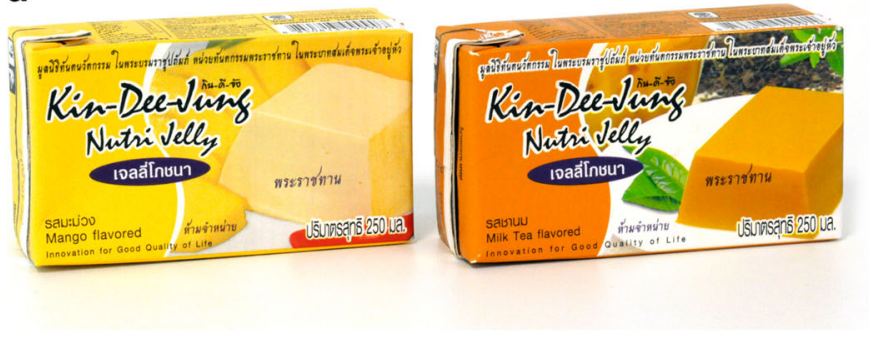

b
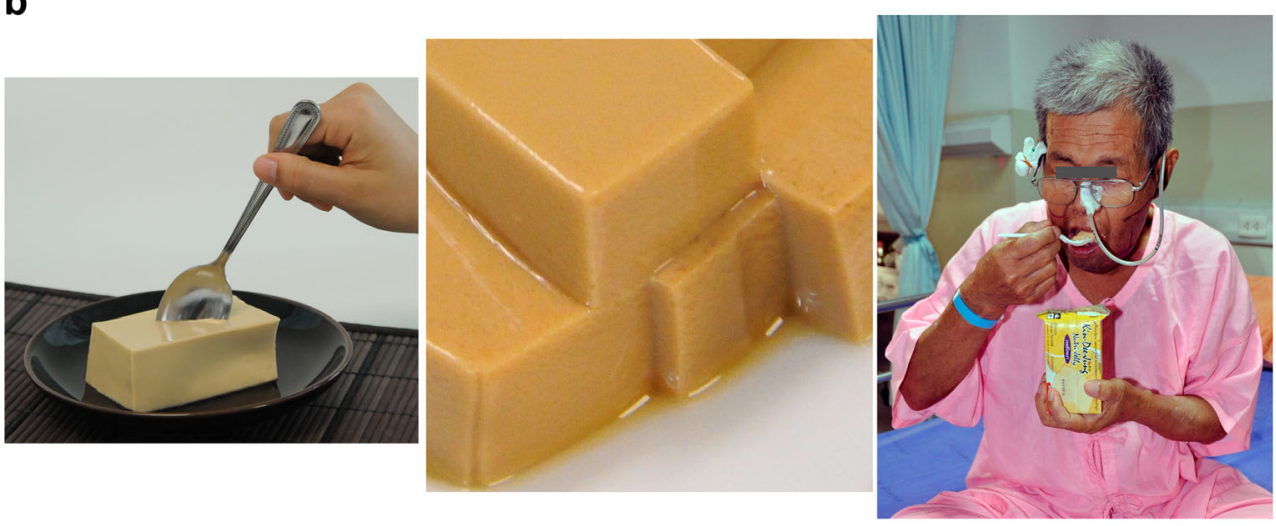

C

\begin{tabular}{|c|c|c|c|}
\hline \multicolumn{2}{|c|}{\begin{tabular}{l}
\multicolumn{1}{c}{ Nutrition fact } \\
Nutri-jelly (mango flavored) \\
Serving size: 1 ( $250 \mathrm{ml}, 235.5 \mathrm{~g}$ ) \\
Servings per container: 1 \\
Total energy per serving $260 \mathrm{kcal}$ \\
(energy from fat $70 \mathrm{kcal}$ )
\end{tabular}} & \multicolumn{2}{|c|}{\begin{tabular}{l}
\multicolumn{1}{c}{ Nutrition fact } \\
Nutri-jelly (milk tea flavored) \\
Serving size: $1(250 \mathrm{ml}, 235.5 \mathrm{~g})$ \\
Servings per container: 1 \\
Total energy per serving $230 \mathrm{kcal}$ \\
(energy from fat $60 \mathrm{kcal}$ )
\end{tabular}} \\
\hline \multicolumn{2}{|c|}{ Percent Thai RDI* } & \multicolumn{2}{|c|}{ Percent Thai RDI } \\
\hline Total fat $8 \mathrm{~g}$ & $12 \%$ & Total fat $7 \mathrm{~g}$ & $11 \%$ \\
\hline Saturated fat $2.5 \mathrm{~g}$ & $12 \%$ & Saturated fat $2 \mathrm{~g}$ & $10 \%$ \\
\hline $\begin{array}{l}\text { Cholesterol } 30 \mathrm{mg} \\
\text { Protein } 11 \mathrm{~g}\end{array}$ & $10 \%$ & $\begin{array}{l}\text { Cholesterol } 15 \mathrm{mg} \\
\text { Protein } 10 \mathrm{~g}\end{array}$ & $5 \%$ \\
\hline Total carbohydrate $37 \mathrm{~g}$ & $12 \%$ & Total carbohydrate $32 \mathrm{~g}$ & $11 \%$ \\
\hline $\begin{array}{l}\text { Dietary fiber } 1 \mathrm{~g} \\
\text { Sugars } 24 \mathrm{~g}\end{array}$ & $4 \%$ & $\begin{array}{l}\text { Dietary fiber }<1 \mathrm{~g} \\
\text { Sugars } 9 \mathrm{~g}\end{array}$ & $3 \%$ \\
\hline Sodium $115 \mathrm{mg}$ & $5 \%$ & Sodium $140 \mathrm{mg}$ & $6 \%$ \\
\hline Vitamin A & $15 \%$ & Vitamin A & $10 \%$ \\
\hline Vitamin B & $20 \%$ & Vitamin B & $25 \%$ \\
\hline Iron< & $2 \%$ & Iron & $0 \%$ \\
\hline Vitamin B1 & $10 \%$ & Vitamin B1 & $8 \%$ \\
\hline Calcium & $30 \%$ & Calcium & $30 \%$ \\
\hline
\end{tabular}

completed data were from 74 patients $(92.5 \%$ ) composing of 37 patients in study group and 37 patients in control groups.

Study procedures

This study was approved by the institutional ethics committee for research in human of Mahavachiralongkorn Cancer Hospital and performed according to the Declaration of Helsinki. As the first study to investigate the possible benefit of Nutri-jelly, adherence to Nutri-jelly intake during 5-7 weeks of RT was absolutely required. In clinical trials, evidences showed that patients who received their preferred treatment might be better motivated, complied with treatment program, and report more reliable outcomes [20]. Therefore, in this study, we used a prospective quasirandomized patient-preference trial (PPT) design [20]. Patients who passed the inclusion criteria and signed the written informed 
consent were assigned to study or control groups based on their preference for continuous Nutri-jelly intake. To prevent selection bias and avoid ethical issues, all subjects had equal chance to try a few spoon of Nutri-jelly at the beginning ( $0-5$ RT fractions, before having any complications from RT). Patients who accepted and rejected to continuously take Nutri-jelly were assigned into study and control groups, respectively. The reasons for rejection were unsatisfied to taste and appearance. Baseline HRQOL, baseline body mass index, and demographic characteristics of patients in study group were compared with those of control group to ensure that both groups were homogeneous. The study group received radiotherapy and a 200-ml box of Nutri-jelly as daily supplement throughout radiation course (57 weeks). In contrast, the control group received only standard radiotherapy. Their HRQOL scores were assessed at every $5 \mathrm{RT}$ fractions. The study was single-blinded for outcome assessor.

\section{Outcome measure}

The primary outcome was HRQOL. The secondary outcome was percentage of tube feeding use.

\section{Health-related quality of life assessment}

HRQOL scores were assessed at every 5 RT fractions (once a week for 5-7 weeks). Thus, the tool should be informative but as concise as possible. Unfortunately, widely accepted questionnaires such as European Organization for Research and Treatment of Cancer core quality of life questionnaire (EORTC QLQ-C30) with Head and Neck cancer (H\&N 35) or Functional Assessment of Cancer Therapy-Head and Neck (FACT-HN) contain excessive questions (65 and 39 items, respectively), which was not feasible for weekly assessment of patients during radiotherapy. Therefore, we developed a new 14-item questionnaire and validated it in head and neck cancer patients. This tool aimed to evaluate physiologic, psychologic, and social aspects of HRQOL, as previously published [5, 21]. However, this questionnaire only included physiologic domains strongly associated with weight loss as reported [22] and common psychosocial problems for head and neck cancer patients suggested by experienced caregivers. The tool included 14 questions asking how bothersome of each problem. The problem score ranged from 0 (no problems) to 10 (most troublesome). The HRQOL score of each domain was the subtraction of averaged problem score from ten. Overall HRQOL score of each subject was calculated as the mean of all domain scores. Content validation was analyzed by Lynn method [23]. Five evaluators included dentist, radiation oncologist, oncology nurse, nutritionist, and expert in quality of life measurement. The questionnaire was revised until all experts gave favorable score to all items ( $\geq 3$ out of score 5). The final version had content validation index of 1 and reliability index (Cronbach's alpha) of 0.9. The questionnaire was shown in Online Resource.

\section{Tube feeding use}

Before starting the trial, none of patients in both groups had used tube feeding for nutritional supports. During radiotherapy, admission for NG tube feeding was obtained from medical records. Percentage of tube feeding in study and control groups was calculated from the number of patients receiving tube feeding during radiotherapy compared to all patients in their respective groups.

\section{Statistical analysis}

Sample size and power were calculated by G Power 3.1. Graphing and statistical analysis were performed by GraphPad Prism 5.0. Normality of data distribution was verified by D'Agostino and Pearson omnibus test. Parametric statistical tests were used only when the data passed normality test $(p>0.05)$. Comparison of baseline quality of life (overall and domain-specific), age, and domain-specific health-related quality of life scores in study and control groups was analyzed by independent $t$ test. Comparison of their baseline body mass index (BMI) and certain domain-specific health-related quality of life scores was analyzed by Mann-Whitney test. Comparison of categorical data between study and control groups (e.g., frequency in tube feeding use, baseline demographic data, etc.) was analyzed by chi-square or Fisher's exact test. Changes of overall HRQOL score over time of radiation were analyzed by one-way ANOVA and Bonferroni test. Comparison of overall HRQOL between study and control groups at various time points was analyzed by two-way ANOVA and Bonferroni test. All tests were performed with two-tailed, $\alpha=0.05$. A $p$ value $<0.05$ was considered statistically significant. At the end, post hoc power analysis was performed to confirm that the sample size was enough to gain at least $90 \%$ power of for all test.

\section{Results}

Baseline data

Initially, 80 patients were enrolled. Then, six patients were dropped out (four from control group and two from study group) due to loss of follow-up and incomplete data. Finally, completed data were from 74 patients ( $92.5 \%$ retention) composing of 37 patients in study group and 37 patients in control groups.

All baseline demographic data and illness characteristics of both groups were not different $(p>0.05)$ (Table 1). Baseline overall HRQOL scores in study and control groups were relatively similar (7.52 and 7.73, respectively, $p=0.73$ ). 
Table 1 Characteristics of patients in study and control groups

\begin{tabular}{|c|c|c|c|c|c|c|c|c|}
\hline \multirow[t]{2}{*}{ Characteristic } & & \multicolumn{3}{|c|}{ Study group $(n=37)$} & \multicolumn{3}{|c|}{ Control group $(n=37)$} & \multirow[t]{2}{*}{$p$ value } \\
\hline & & $N$ & $\%$ & Mean \pm sd. & $N$ & $\%$ & Mean \pm sd. & \\
\hline \multicolumn{2}{|l|}{ Baseline overall quality of life } & & & $7.52 \pm 1.35$ & & & $7.73 \pm 1.8$ & $0.73^{\mathrm{a}}$ \\
\hline \multicolumn{2}{|c|}{ Baseline body mass index (BMI) } & & & $22.09 \pm 4.87$ & & & $21.58 \pm 5.16$ & $0.58^{\mathrm{b}}$ \\
\hline \multicolumn{2}{|l|}{ Age } & & & $56.95 \pm 10.92$ & & & $53.7 \pm 12.66$ & $0.24^{\mathrm{a}}$ \\
\hline Sex & $\begin{array}{l}\text { Male } \\
\text { Female }\end{array}$ & $\begin{array}{l}26 \\
11\end{array}$ & $\begin{array}{l}70.27 \\
29.73\end{array}$ & & $\begin{array}{l}24 \\
13\end{array}$ & $\begin{array}{l}64.86 \\
35.14\end{array}$ & & $0.80^{\mathrm{c}}$ \\
\hline Marital status & $\begin{array}{l}\text { Single } \\
\text { Married/widow/divorced }\end{array}$ & $\begin{array}{l}9 \\
28\end{array}$ & $\begin{array}{l}24.32 \\
75.68\end{array}$ & & $\begin{array}{l}8 \\
29\end{array}$ & $\begin{array}{l}21.62 \\
78.38\end{array}$ & & $0.78^{\mathrm{d}}$ \\
\hline Religion & $\begin{array}{l}\text { Buddhism } \\
\text { Christ/Islam }\end{array}$ & $\begin{array}{l}35 \\
2\end{array}$ & $\begin{array}{l}94.59 \\
5.41\end{array}$ & & $\begin{array}{l}35 \\
2\end{array}$ & $\begin{array}{l}94.59 \\
5.41\end{array}$ & & $1.00^{\mathrm{c}}$ \\
\hline \multirow[t]{2}{*}{ Education } & $\begin{array}{l}\text { Primary school } \\
\text { Secondary school }\end{array}$ & $\begin{array}{l}25 \\
8\end{array}$ & $\begin{array}{l}67.57 \\
21.62\end{array}$ & & $\begin{array}{l}22 \\
10\end{array}$ & $\begin{array}{l}59.46 \\
27.03\end{array}$ & & \multirow[t]{2}{*}{$0.77^{\mathrm{d}}$} \\
\hline & Undergraduate and graduate & 4 & 10.81 & & 5 & 13.51 & & \\
\hline Occupation & $\begin{array}{l}\text { Physically active (agriculture, laborer) } \\
\text { Nonphysically active (unemployed, housewife, monk, } \\
\text { retired, government, business,) }\end{array}$ & $\begin{array}{l}15 \\
22\end{array}$ & $\begin{array}{l}40.54 \\
59.46\end{array}$ & & $\begin{array}{l}13 \\
24\end{array}$ & $\begin{array}{l}35.14 \\
64.86\end{array}$ & & $0.81^{\mathrm{c}}$ \\
\hline \multirow[t]{2}{*}{ Monthly income } & $\begin{array}{l}<5,000 \text { baht } \\
5,000-20,000 \text { baht }\end{array}$ & $\begin{array}{l}21 \\
13\end{array}$ & $\begin{array}{l}56.76 \\
35.14\end{array}$ & & $\begin{array}{l}20 \\
13\end{array}$ & $\begin{array}{l}54.05 \\
35.14\end{array}$ & & \multirow[t]{2}{*}{$0.92^{\mathrm{d}}$} \\
\hline & $>20,000$ baht & 3 & 8.11 & & 4 & 10.81 & & \\
\hline \multirow[t]{2}{*}{ Health insurance } & $\begin{array}{l}\text { National health care } \\
\text { Social insurance/government benefit }\end{array}$ & $\begin{array}{l}29 \\
7\end{array}$ & $\begin{array}{l}78.38 \\
18.92\end{array}$ & & $\begin{array}{l}31 \\
5\end{array}$ & $\begin{array}{l}83.78 \\
13.51\end{array}$ & & \multirow[t]{2}{*}{$0.75^{\mathrm{d}}$} \\
\hline & Self-payment & 1 & 2.70 & & 1 & 2.70 & & \\
\hline \multirow[t]{2}{*}{ Primary site } & $\begin{array}{l}\text { Lip/oral cavity/oropharynx } \\
\text { Nasopharynx/maxillary sinus }\end{array}$ & $\begin{array}{l}18 \\
9\end{array}$ & $\begin{array}{l}48.65 \\
24.32\end{array}$ & & $\begin{array}{l}18 \\
11\end{array}$ & $\begin{array}{l}48.65 \\
29.73\end{array}$ & & \multirow[t]{2}{*}{$0.81^{\mathrm{d}}$} \\
\hline & Other head and neck areas & 10 & 27.03 & & 8 & 21.62 & & \\
\hline Clinical stage & $\begin{array}{l}\text { Early (I-II) } \\
\text { Late (III-IV) }\end{array}$ & $\begin{array}{l}7 \\
30\end{array}$ & $\begin{array}{l}18.92 \\
81.08\end{array}$ & & $\begin{array}{l}9 \\
28\end{array}$ & $\begin{array}{l}24.32 \\
75.68\end{array}$ & & $0.78^{\mathrm{c}}$ \\
\hline \multirow[t]{2}{*}{ Previous treatment of cancer } & $\begin{array}{l}\text { None } \\
\text { Surgery }\end{array}$ & $\begin{array}{l}23 \\
11\end{array}$ & $\begin{array}{l}62.16 \\
29.73\end{array}$ & & $\begin{array}{l}21 \\
12\end{array}$ & $\begin{array}{l}56.76 \\
32.43\end{array}$ & & \multirow[t]{2}{*}{$0.87^{\mathrm{d}}$} \\
\hline & Radiotherapy/chemotherapy & 3 & 8.11 & & 4 & 10.81 & & \\
\hline Treatment plan & $\begin{array}{l}\text { Concurrent chemoradiotherapy } \\
\text { Radiotherapy only }\end{array}$ & $\begin{array}{l}4 \\
33\end{array}$ & $\begin{array}{l}10.81 \\
89.19\end{array}$ & & $\begin{array}{l}5 \\
32\end{array}$ & $\begin{array}{l}13.51 \\
86.49\end{array}$ & & $0.72^{\mathrm{c}}$ \\
\hline Radiation dose & $\begin{array}{l}7,000 \text { cGy ( } 35 \text { fractions) } \\
3,600-6,000 \text { cGy ( } 18-30 \text { fractions })\end{array}$ & $\begin{array}{l}30 \\
7\end{array}$ & $\begin{array}{l}81.08 \\
18.92\end{array}$ & & $\begin{array}{l}30 \\
7\end{array}$ & $\begin{array}{l}81.08 \\
18.92\end{array}$ & & $1.00^{\mathrm{c}}$ \\
\hline
\end{tabular}

${ }^{\mathrm{a}} p$ value from independent $t$ test

${ }^{\mathrm{b}}$ Mann-Whitney test

'Fishers' exact test

${ }^{\mathrm{d}}$ Chi-square test

Analysis of domain-specific HRQOL showed that baseline HRQOL scores of all domains in both groups were similar (Table 2). As shown in Table 1, at baseline, BMI in both groups was quite similar (22.09 and 21.58, respectively, $p=0.58$ ) and considered as normal nutrition status for Thai healthy adults (BMI, 18-25). Therefore, at baseline, none of the patients required NG tube feeding. Most of the participants in both study and control groups were male Buddhists with average age of 56.95 and 53.7 years, respectively. Most of them were married and graduated from primary school. More than half of them were unemployed or having nonphysically active jobs with monthly income less than 5,000 Thai baht. The cancer treatment expense of most patients in both groups was covered by National health care plan which was totally free of charge. Almost half of patients were diagnosed with primary lip/oral cavity or oropharyngeal cancer, while the rest had cancer in nasopharynx and other area. A majority of patients in both group had cancer in late stage, and more than half of them had never been treated. Most of patients in both groups would receive definitive radiotherapy only, while a small number (10.81 and $13.51 \%$, respectively) would receive concurrent chemoradiotherapy. Eighty-one percent of 
Table 2 Baseline quality of life in study and control groups: domain specific

\begin{tabular}{llll}
\hline Domain & $\begin{array}{l}\text { Study group } \\
\text { (mean } \pm \mathrm{sd} \text { ) }\end{array}$ & $\begin{array}{l}\text { Control group } \\
(\text { mean } \pm \mathrm{sd})\end{array}$ & $p$ value* \\
\hline Mouth pain & $7.19 \pm 2.45$ & $8.35 \pm 2.69$ & 0.18 \\
Burning mouth & $8.77 \pm 1.88$ & $8.92 \pm 2.66$ & 0.36 \\
Swallowing difficulty & $6.50 \pm 3.18$ & $6.42 \pm 4.13$ & 0.83 \\
Dry mouth & $6.00 \pm 3.13$ & $7.30 \pm 3.16$ & 0.22 \\
Trismus & $7.16 \pm 2.98$ & $6.81 \pm 3.69$ & 0.73 \\
Taste alteration & $6.04 \pm 2.96$ & $6.58 \pm 3.68$ & 0.60 \\
Overall eating problems & $6.08 \pm 3.24$ & $6.60 \pm 3.70$ & 0.59 \\
Mouth odor & $8.62 \pm 2.22$ & $9.43 \pm 1.50$ & 0.21 \\
Tired easily & $7.77 \pm 2.45$ & $6.85 \pm 2.93$ & 0.14 \\
Fatigue & $8.08 \pm 2.17$ & $7.54 \pm 2.07$ & 0.47 \\
Discouraged & $8.71 \pm 2.45$ & $9.54 \pm 1.13$ & 0.47 \\
Limited daily activity & $6.92 \pm 3.77$ & $6.95 \pm 3.47$ & 0.97 \\
Social isolation & $9.12 \pm 1.96$ & $9.15 \pm 1.86$ & 0.97 \\
Appearance & $8.81 \pm 2.29$ & $7.92 \pm 3.18$ & 0.69 \\
\hline
\end{tabular}

*The significance of differences was statistically tested by independent $t$ test

patients in both groups would receive 7,000 cGy of Cobalt-60 radiation, which required $35 \mathrm{RT}$ fractions and 7 weeks treatment period.

Effect of Nutri-jelly on overall health-related quality of life

To evaluate the effect of Nutri-jelly on quality of life, changes in overall HRQOL score of study group were compared with those of control group. As shown in Fig. 2a, after receiving radiotherapy, the average overall HRQOL score in the control group significantly decreased in a dose-dependent manner $(p<0.0001)$. Bonferroni post hoc test showed that the significant differences in HRQOL compared to baseline score were found from 16 to 35 fractions of RT (3,200-7,000 cGy). This suggested that overall quality of life in head and neck cancer patients was reduced over time during radiotherapy. In contrast, in Fig. 2b, the average overall HRQOL scores in study group were not significantly different from baseline throughout the study ( $p=0.8891)$. In Fig. 2c, comparative analysis between study and control groups showed that at the beginning (0-5 RT fractions) before receiving Nutri-jelly, the mean overall HRQOL scores of both groups were not different (7.5 vs 7.73, respectively, $p>0.05$ ). However, after receiving $11-$ 35 fractions of RT, the overall HRQOL score in study group was significantly higher than that of the control group $(p<0.0001)$. The highest significant difference was found at 26-35 RT fractions, which was the last period of treatment. This data suggests that continuous intake of Nutri-jelly during definitive radiotherapy may improve overall health-related quality of life in head and neck cancer patients.
Effect of Nutri-jelly on domain-specific health-related quality of life

Since the difference in overall HRQOL score between study and control groups was significant during 11-35 fractions of RT, we further identified which specific domains of HRQOL could be improved by Nutri-jelly. In Table 3, means of each domain scores in study and control groups were compared. Interestingly, from 11 to 20 fractions, there were several physiologic domains with significantly better score in the study group at certain time points. These included mouth pain, swallowing difficulty, dry mouth, trismus, taste alteration, and overall eating problems. In addition to those domains, from 21 to 35 RT fractions, some more physiologic domains were improved in the study group, i.e., burning mouth, mouth odor, tired easily, fatigue, and interference with daily activities. Also, psychological domain such as discouraged was improved during this period. Importantly, the domains that significantly improved at all time points of radiation were swallowing difficulty and overall eating problems. The most striking differences between study and control groups were found in 26-35 RT fractions in which HRQOL score of almost all domains became significantly better. In contrast, there were no significant changes of social domains such as social isolation and confidence in appearance in both study and control groups. These data suggested that continuous intake of Nutrijelly may improve physiologic and psychological aspects of HRQOL in head and neck cancer patients, during the middle and late phases of radiotherapy (11-35 RT fractions).

\section{Effect of Nutri-jelly on tube feeding use}

At baseline (0-5 RT fractions), average BMI of patients in both groups indicated normal nutritional status, and none of the patients received NG tube feeding. As shown in Table 4, during radiotherapy (6-35 RT fractions), there were $48.6 \%$ of patients in control group admitted for NG tube feeding, while only $13.5 \%$ of patients in the study group were tube-fed. Statistical analysis demonstrated that the difference was highly significant $(p=0.0045)$. Taken together, these data suggested that continuous intake of Nutri-jelly during RT may decrease hospital admission for NG tube feeding.

\section{Discussion}

Eating difficulty is a critical problem in head and neck cancer patients since it could lead to malnutrition, poor quality of life, and poor treatment response [24, 25]. Nutritional status is a strong predictor for quality of life in cancer patients before and after treatment [26-28]. Nutritional intervention such as tube feeding was found to improve overall quality of life; however, 
Fig. 2 Effect of Nutri-jelly intake during radiotherapy on overall HRQOL. a-b Changes of HRQOL scores during RT in control group (a) and study group (b). Each bar represented mean quality of life score at different time of RT. Error bars indicated standard deviation (SD). Oneway ANOVA test showed significant difference in control group $(p<0.0001)$ and no significant difference in study group ( $p=0.8891)$. Bonferroni test identified time points with significant difference from baseline. c Comparison between study and control group. Each point represented mean quality of life score at different time of radiotherapy. Error bars indicated standard deviation (SD). Control group (radiotherapy only) (white square); study group (radiotherapy and one box of Nutri-jelly/day) (black square). Two-way ANOVA showed difference $(p<0.0001)$, followed by Bonferroni test. * $p<0.05$; $* * p<0.01 ; * * * p<0.001$ a

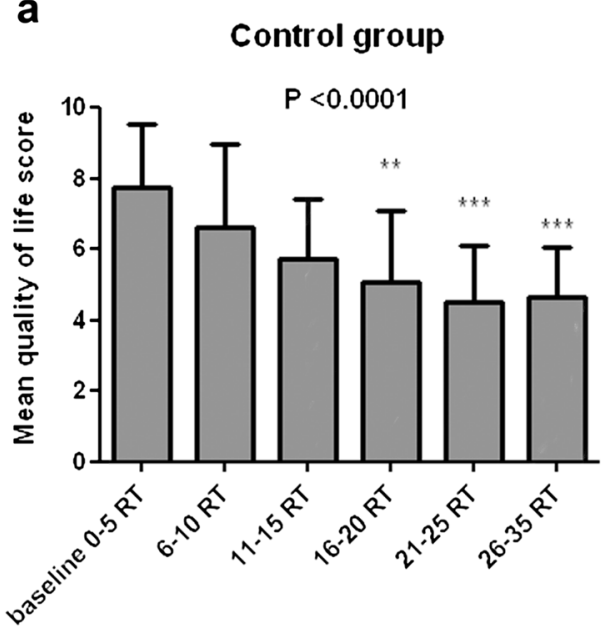

b

b Study group

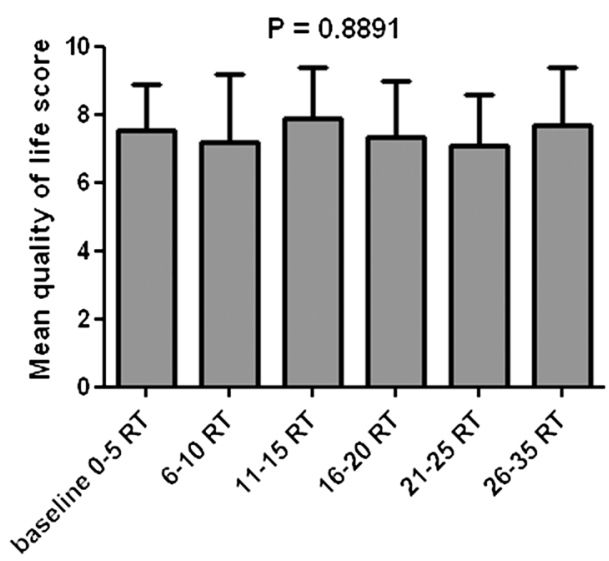

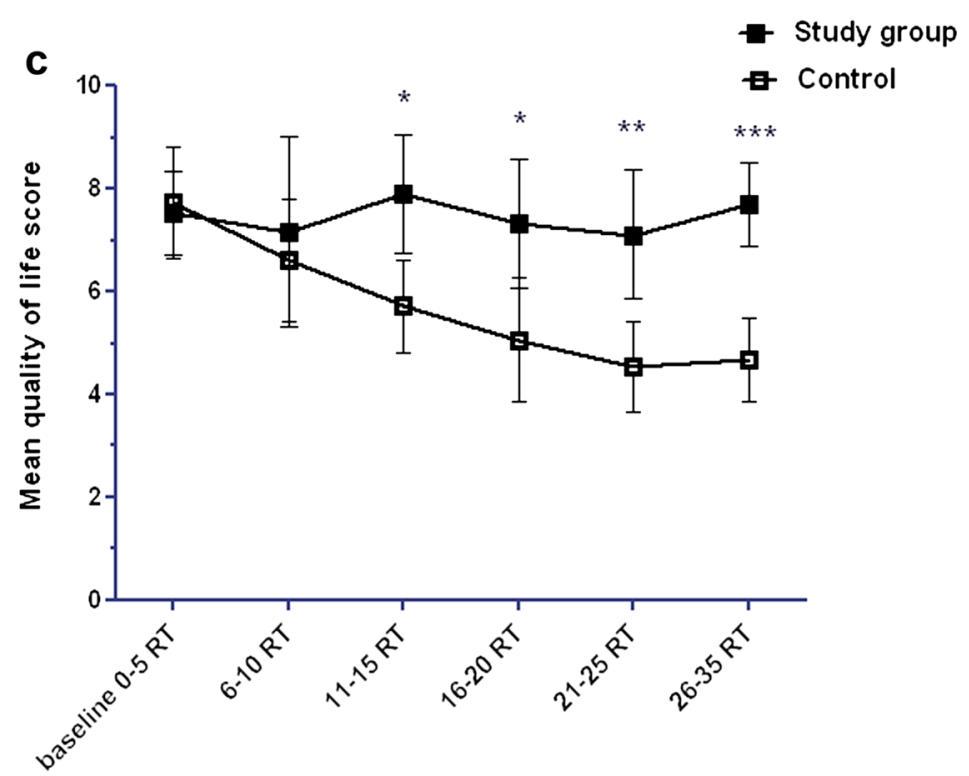

Fractions of Radiation treatment

the procedure is invasive [29]. Furthermore, deprivation of chewing and swallowing contributed to distress in tube-fed patients [30]. Using prospective quasi-randomized patientpreference trial design with control group comparison, here, we reported that continuous supplementation of Nutri-jelly throughout radiotherapy may improve HRQOL and reduce tube feeding demand in head and neck cancer patients who preferred to take them. The promising result renders us to pursue further randomized studies. Systemic reviews suggest that random allocation of patients with preferences into study or control group may affect the internal validity and outcome of the controlled trial [31]. Therefore, future randomized controlled study should be performed in patients who preferred to take Nutri-jelly.

Unlike many other oral supplements, Nutri-jelly is readyto-eat, solid-like, moisten, chewable, and easy to swallow [17]. These properties make it suitable for patients with eating difficulty and dry mouth such as cancer patients undergoing radiotherapy. Since swallowing ability and overall eating were the domains of HRQOL most significantly improved by Nutri-jelly, the favorable outcome in overall HRQOL likely resulted mainly from increased oral intake. Consistently, previous studies reported that ingestion of oral nutritional supplements could improve certain aspects of quality of life [12]. However, currently marketed supplements still could not improve patients' survival [12]. Here, Nutri-jelly was found to improve multiple domains of HRQOL including swallowing, mouth pain, and discouragement. Coincidentally, these exact domains were reported as good predictors for survival of head and neck cancer patients [16]. This result encourages further investigation of the effect of Nutri-jelly on survival of cancer patients.

From 16 to 35 fractions of RT (3,200-7,000 cGy), subjects in the control group had significant decrease in overall 
Table 3 Domain-specific health-related quality of life score

\begin{tabular}{|c|c|c|c|c|c|c|c|c|c|c|c|c|}
\hline \multirow[t]{2}{*}{ Domain } & \multicolumn{3}{|c|}{$11-15$ RT fractions } & \multicolumn{3}{|c|}{ 16-20 RT fractions } & \multicolumn{3}{|c|}{ 21-25 RT fractions } & \multicolumn{3}{|c|}{ 26-35 RT fractions } \\
\hline & $\begin{array}{l}\text { Study } \\
\text { group }\end{array}$ & $\begin{array}{l}\text { Control } \\
\text { group }\end{array}$ & $p$ value* & $\begin{array}{l}\text { Study } \\
\text { group }\end{array}$ & $\begin{array}{l}\text { Control } \\
\text { group }\end{array}$ & $p$ value* & $\begin{array}{l}\text { Study } \\
\text { group }\end{array}$ & $\begin{array}{l}\text { Control } \\
\text { group }\end{array}$ & $p$ value* & $\begin{array}{l}\text { Study } \\
\text { group }\end{array}$ & $\begin{array}{l}\text { Control } \\
\text { group }\end{array}$ & $p$ value* \\
\hline Mouth pain & 5.22 & 3.56 & ns & 6.44 & 3.04 & 0.011 & 5.00 & 1.70 & 0.004 & 5.00 & 2.93 & 0.043 \\
\hline Burning mouth & 6.22 & 4.06 & ns & 6.44 & 5.75 & ns & 5.75 & 1.93 & 0.003 & 6.63 & 3.18 & 0.002 \\
\hline Swallowing difficulty & 6.78 & 3.27 & 0.005 & 5.28 & 2.79 & 0.025 & 5.69 & 1.93 & 0.0006 & 6.18 & 3.21 & 0.006 \\
\hline Dry mouth & 7.00 & 3.28 & 0.004 & 5.67 & 4.32 & ns & 5.81 & 2.30 & 0.002 & 5.36 & 3.14 & 0.031 \\
\hline Trismus & 8.28 & 5.34 & 0.024 & 7.33 & 5.43 & ns & 7.19 & 6.07 & ns & 7.16 & 4.54 & 0.022 \\
\hline Taste alteration & 8.83 & 4.41 & 0.001 & 5.67 & 4.17 & ns & 5.25 & 2.60 & 0.030 & 7.24 & 2.93 & 0.0003 \\
\hline Overall eating problems & 5.67 & 3.25 & 0.045 & 5.89 & 1.71 & $<0.0001$ & 4.19 & 1.27 & 0.005 & 5.97 & 2.36 & 0.001 \\
\hline Mouth odor & 8.89 & 7.31 & ns & 8.56 & 7.29 & ns & 8.13 & 6.80 & ns & 8.58 & 6.43 & 0.049 \\
\hline Tired easily & 9.11 & 7.13 & ns & 8.44 & 6.39 & ns & 8.94 & 5.80 & 0.024 & 9.39 & 5.00 & $<0.0001$ \\
\hline Fatigue & 8.00 & 7.00 & ns & 8.00 & 6.43 & ns & 8.50 & 5.73 & ns & 9.37 & 5.43 & $<0.0001$ \\
\hline Discouraged & 9.56 & 7.81 & ns & 9.33 & 7.00 & ns & 9.88 & 6.80 & $<0.0001$ & 9.74 & 6.38 & 0.0004 \\
\hline Limited daily activity & 7.89 & 5.56 & ns & 7.44 & 4.82 & ns & 7.25 & 4.53 & ns & 8.81 & 3.85 & $<0.0001$ \\
\hline Social isolation & 9.67 & 9.00 & ns & 8.11 & 6.21 & ns & 8.13 & 6.93 & ns & 8.40 & 7.57 & ns \\
\hline Appearance & 9.44 & 8.63 & ns & 9.78 & 8.57 & ns & 9.75 & 8.40 & ns & 9.68 & 8.43 & ns \\
\hline
\end{tabular}

The table shows mean of HRQOL scores in each domain at different time points of radiotherapy, comparing that of study group and control group $n s$ not statistically significant $(p>0.05)$

*The significance of differences was statistically tested by independent $t$ test. At the points where statistical significance was found $(p<0.05)$, the $p$ values were shown

HRQOL. This was mainly due to decrease in scores of oral physiologic domains such as mouth pain, burning, taste loss, trismus, and dry mouth. Consistently, these RT doses are known to cause oral side effects including oral mucositis, loss of tongue papillae, muscle fibrosis, and acinar cell death in salivary glands [1,32]. Therefore, the decline in overall HRQOL was likely due to those oral sequelae of radiation. Importantly, these could lead to chewing and swallowing difficulty, and poor quality of life [33]. In contrast to the control group, subjects in the study group could maintain HRQOL score of those oral domains throughout RT, without significant decrease. This might explain the observed effect of Nutri-jelly in improving swallowability and overall eating domains at all time points of radiation.

Our study exploited "standard therapy with no intervention" as the control group. Therefore, all patients of both groups inevitably recognized whether they took Nutri-jelly.

Table 4 Nasogastric (NG) tube feeding use during definitive radiation therapy

\begin{tabular}{llll}
\hline & Study group & Control group & $p$ value* \\
\hline NG tube feeding & $5(13.5 \%)$ & $18(48.6 \%)$ & \\
Self-oral intake & $32(86.5 \%)$ & $19(51.4 \%)$ & \\
Total & $37(100 \%)$ & $37(100 \%)$ & 0.0045 \\
\hline
\end{tabular}

*The significance of differences between study and control groups was statistically tested by Fishers' exact test
Since low eating ability was correlated with depression [34, 35], realizing that they can eat Nutri-jelly by mouth may encourage the patients in study group to better tolerate treatment side effects. Although they may have similar oral conditions as control group, they might feel less bothered by those problems. Thus, the observed improvement in HRQOL may partly result from psychological effect of Nutri-jelly.

Based on the data, Nutri-jelly may significantly improve swallowing difficulty and overall eating domains of HRQOL. The mechanism for this effect probably results from its unique physical properties. Compared to currently available nutritional supplements, Nutri-jelly has solid-like appearance, more resembling to regular food. Furthermore, the syneresis property (water released from gel upon biting or spooning) of Nutri-jelly might rehydrate the dry mouth of patients, overcoming the limitation of those thickened liquid used in dysphagia treatment [15]. Future randomized controlled trial comparing Nutri-jelly with marketed liquid food products is warranted to confirm this hypothesis. Also, stimulation of salivary flow rate should be measured in the future study.

Nutri-jelly has 230-260 kcal/box, considered as a nutritional supplement. Therefore, it is not intended to replace NG tube feeding. Instead, it rather prevents or delays the need of NG tube use. In control group of this study, increasing dose of radiation resulted in oral dysfunction and eating impairment, evidenced by a significant decline in overall eating domain of HRQOL score. Inadequate oral intake leads to weight loss, malnutrition, and eventually requirement for $\mathrm{NG}$ tube feeding 
[36]. In contrast, the study group received Nutri-jelly as supplement from the beginning until the end of RT. Even when their ability to eat regular diet was impaired, most of them could still eat edible soft diet supplemented by Nutri-jelly, thereby maintaining overall eating HRQOL score. This notion is based on a parallel study by Karapoch et al. that during radiotherapy, the study group exhibited less percentage of weight loss than control group due to better maintenance of overall dietary intake [37]. These findings might explain how Nutri-jelly supplement may reduce tube-feeding demand.

A study commented that oral intake while wearing NG tube feeding may be possible [38]. However, there are no supporting evidences in cancer patients. Here, we observed that a few patients in study group could still take Nutri-jelly orally while wearing the tube. Interestingly, their HRQOL scores were better than NG-tube-fed patients in control group (during 6-15 RT: average of 8.7, compared to 6.7, and during 20-35 RT: average of 6 compared to 4.8). Since preventive chewing and swallowing exercises may accelerate restoration of eating ability after tube removal [39]. Further studies are warrant to investigate the effect of Nutri-jelly on HRQOL and swallowing recovery in NG tube-fed patients.

Eating difficulty is found not only in cancer patients but also in other groups such as dental disease, tooth loss, jaw surgery, stroke, and Parkinson's disease [40]. Thus, Nutri-jelly may benefit to a broad range of patients. In conclusion, Nutrijelly is a new oral nutritional supplement with potential clinical application, deserving further exploration.

Acknowledgments The authors thank Dr. Samrit Saekow, Ms Pijit Trachootham, Ms Kuarada Chaturat, and Ms Jenjira Chotasi for research assistance; Professor Tan-Phu-Ying Petchara Techakamput, Mr Chankit Santikasem, Dr. Pattawee Kongkoontian, and Mr Worawut Kulkaew for support and suggestions; Assoc. Prof. Dr. Visith Chavasitt, Asst. Prof. Dr. Wantanee Kriengsinyos, Dr. Nattapol Tangsuphoom, Ms Wannee Jaturachamroenchai, and Ms Panitnart Kanjanatiwat for product development.

Conflict of interest The research expense in this study was supported by Dental Innovation Foundation under royal patronage, a nonprofit organization. No authors have financial relationship with the product manufacturer. The authors have full control of all primary data and have agreed to allow the journal to review the data if requested.

Open Access This article is distributed under the terms of the Creative Commons Attribution Noncommercial License which permits any noncommercial use, distribution, and reproduction in any medium, provided the original author(s) and the source are credited.

\section{References}

1. Vissink A, Jansma J, Spijkervet FK, Burlage FR, Coppes RP (2003) Oral sequelae of head and neck radiotherapy. Crit Rev Oral Biol Med 14:199-212
2. Epstein JB, Huhmann MB (2012) Dietary and nutrition needs of patients after therapy for head and neck cancer. J Am Dent Assoc 143(6):588-592

3. Hayward MC, Shea AM (2009) Nutritional needs of patients with malignancies of the head and neck. Semin Oncol Nurs 25:203-211. doi:10.1016/j.sonen.2009.05.003

4. Gurney TA, Eisele DW, Orloff LA, Orloff LA, Wang SJ (2008) Predictors of quality of life after treatment for oral cavity and oropharyngeal carcinoma. Otolaryngol Head Neck Surg 139(2):262267. doi:10.1016/j.otohns.2008.05.024

5. Ramaekers BL, Joore MA, Grutters JP, Van den Ende P, Jd J, Houben $R$ et al (2011) The impact of late treatment-toxicity on generic healthrelated quality of life in head and neck cancer patients after radiotherapy. Oral Oncol 47(8):768-774. doi:10.1016/j. oraloncology. 2011.05.012

6. Epstein JB, Thairat J, Bensadoun RJ, Barasch A, Murphy BA, Kolnick L et al (2012) Oral complications of cancer and cancer therapy: from cancer treatment to survivorship. CA Cancer J Clin 62(6):400-422. doi:10.3322/caac.21157

7. Paccagnella A, Morello M, Da Mosto MC, Baruffi C, Marcon ML, Gava A et al (2010) Early nutritional interventions improves treatment tolerance and outcomes in head and neck cancer patients undergoing concurrent chemoradiotherapy. Support Care Cancer 18(7):837-845. doi:10.1007/s00520-009-0717-0

8. Langius JA, Zandbergen MC, Eerenstein SE, vanTulder MW, Leemans CR, Kramer MH et al (2013) Effect of nutritional interventions on nutritional status, quality of life and mortality in patients with head and neck cancer receiving chemoradiotherapy: a systematic review. Clin Nutr 32(5):671-678. doi:10.1016/j. clnu.2013.06.012

9. Gomes GF, Pisani JC, Macedo ED, Campos AC (2003) The nasogastric feeding tube as a risk factor for aspiration and aspiration pneumonia. Curr Opin Clin Nutr Metab Care 6(3):327-333

10. Koyfman SA, Adelstein DJ (2012) Enteral feeding tubes in patients undergoing definitive chemoradiation therapy for head-and-neck cancer: a critical review. Int J Radiat Oncol Biol Phys 84(3):581589. doi:10.1016/j.ijrobp.2012.03.053

11. Lee H, Havrila C, Bravo V, Shantz K, Diaz K, Larner J et al (2008) Effect of oral nutritional supplementation on weight loss and percutaneous endoscopic gastrostomy tube rates in patients treated with radiotherapy or oropharyngeal carcinoma. Support Care Cancer 16:285-289

12. Baldwin C, Spiro A, Ahern R, Emery PW (2012) Oral nutritional interventions in malnourished patients with cancer: a systematic review and meta-analysis. J Natl Cancer Inst 104(5):371-385. doi: 10.1093/jnci/djr556

13. Ortega O, Parra C, Zarcero S, Nart J, Sakwinska O, Clave' P (2014) Oral health in older patients with oropharyngeal dysphagia. Age Ageing 43(1):132-137. doi:10.1093/ageing/aft164

14. Leibovitz A, Plotnikov G, Habot B, Rosenberg M, Wolf A, Nagler R et al (2003) Saliva secretion and oral flora in prolonged nasogastric tube-fed elderly patients. Isr Med Assoc J 5(5):329-332

15. Cichero JA (2013) Thickening agents used for dysphagia management: effect on bioavailability of water, medication and feelings of satiety. Nutrition J 12(54):1-8

16. Osthus AA, Aarstad AK, Olofsson J, Aarstad HJ (2011) Head and neck specific health related quality of life scores predict subsequent survival in successfully treated head and neck cancer patients: a prospective cohort study. Oral Oncol 47(10):974-979. doi:10.1016/ j.oraloncology.2011.07.010

17. Kanjanatiwat $P$ (2013) Development of nutritious gel for patients with chewing and swallowing difficulties. Thesis, Mahidol University

18. Kunitz M (1928) Syneresis and swelling of gelatin. J Gen Physiol 12(2):289-312

19. Faul F, Erdfelder E, Lang AG, Buchner A (2007) G*Power 3: a flexible statistical power analysis program for the social, behavioral, and biomedical sciences. Behav Res Methods 39:175-191 
20. King M, Nazareth I, Lampe F, Bower P, Chandler M, Morou M et al (2005) Impact of participants and physician intervention preferences on randomised trials; a systemic review. JAMA 293:1089-1099

21. Chen AM, Farwell G, Luu Q, Vazquez EG, Lau DH, Purdy JA (2012) Intensity-modulated radiotherapy is associated with improved global quality of life among long-term survivors of head-and-neck cancer. Int J Radiation Oncol Biol Phys 84(1):170-175. doi:10.1016/ j.ijrobp.2011.11.026

22. Nourissat A, Bairati I, Fortin A, Gélinas M, Nabid A, Brochet F et al (2012) Factors associated with weight loss during radiotherapy in patients with stage I or II head and neck cancer. Support Care Cancer 20(3):591-599. doi:10.1007/s00520-011-1132-x

23. Lynn MR (1986) Determination and quantification of content validity. Nurs Res 35(6):382-385

24. Dearo N, Merlano MC, Russi EG (2013) Dysphagia in head and neck cancer patients: pretreatment evaluation, predictive factors, and assessment during radio-chemotherapy, recommendations. Clin Exp Otorhinolaryngol 6(3):117-126

25. Penner JL, McClement SE, Sawatzky JV (2007) Management of dysphagia in advanced oropharyngeal cancer. Int $\mathrm{J}$ Palliative Nursing 13(5):206-212

26. Lis CG, Gupta D, LammersfeldCA MM, Vashi PG (2012) Role of nutritional status in predicting quality of life outcomes in cancer-a systematic review of the epidemiological literature. Nutrition $\mathrm{J}$ 11(27):1-18

27. Capuano G, Gentile PC, Bianciardi F, Tosti M, Palladino A, Di Palma M (2010) Prevalence and influence of malnutrition on quality of life and performance status in patients with locally advanced head and neck cancer before treatment. Support Care Cancer 18:433-437. doi: 10.1007/s00520-009-0681-8

28. Barrios R, Tsakos G, García-Medina B, Martínez-Lara I, Bravo M (2014) Oral health-related quality of life and malnutrition in patients treated for oral cancer. Support Care Cancer

29. Hossein SM, Leili M, Hossein AM (2011) Acceptability and outcomes of percutaneous endoscopic gastrostomy (PEG) tube placement and patient quality of life. Turk J Gastroenterol 22(2):128-133
30. Padilla GV, Grant M, Wong H, Hansen BW, Hanson RL, Bergstrom $\mathrm{N}$ et al (1979) Subjective distresses of nasogastric tube feeding. JPEN J Parenter Enteral Nutr 3(2):53-57

31. Preference collaborative review group (2008) Patients' preferences within randomized trials: systemic review and patient level metaanalysis. B M J 337:a1864. doi:10.1136/ bmj.a1864

32. Sciubba JJ, Goldenberg D (2006) Oral complications of radiotherapy. Lancet Oncol 7(2):175-183

33. Barrios R, Montero J, González-Moles MA, Baca P, Bravo M (2013) Levels of scientific evidence of the quality of life in patients treated for oral cancer. Med Oral Patol Oral Cir Bucal 18(4):e578-e584

34. Kimura Y, Ogawa H, Yoshihara A, Yamaga T, Takiguchi T, Wada T et al (2013) Evaluation of chewing ability and its relationship with activities of daily living, depression, cognitive status and food intake in the community-dwelling elderly. Geriatr Gerontol Int 13(3):718725. doi:10.1111/ggi.12006

35. Verdonschot RJ, Baijens LW, Serroyen JL, Leue C, Kremer B (2013) Symptoms of anxiety and depression assessed with the hospital anxiety and depression scale in patients with oropharyngeal dysphagia. $\mathrm{J}$ Psychosom Res 75(5):451-455. doi:10.1016/ jjpsychores.2013.08.021

36. Van Cutsem E, Arends J (2005) The causes and consequences of cancer-associated malnutrition. Eur J Oncol Nurs 9:S51-S63

37. Karapoch J (2014) Nutritional status in head and neck cancer patients treated with radiotherapy or chemoradiotherapy and the impact of Nutri-jelly supplement. Thesis, Mahidol University

38. Fattal M, Suiter DM, Warner HL et al (2011) Effect of presence/ absence of a nasogastric tube in the same person on incidence of aspiration. Otolaryngol Head Neck Surg 145(5):796-800. doi:10. 1177/0194599811417067

39. Paleri V, Roe JW, Strojan P (2014) Strategies to reduce long-term postchemoradiation dysphagia in patients with head and neck cancer: an evidence-based review. Head Neck 36(3):431-443. doi:10.1002/ hed.23251

40. Rofes L, Clave' P, Ouyang A, Scharitzer M, Pokieser P, Vilardell N et al (2013) Neurogenic [corrected] and oropharyngeal dysphgia. Ann N Y Acad Sci 1300:1-10. doi:10.1111/nyas.12234 